Ann. Biol. anim. Bioch. Biophys., 1979, 19 (3 B), 949-953.

\title{
Bilan de la digestion des matières azotées du lait et des bactéries cultivées sur méthanol à la fin de l'intestin grêle et du tube digestif du veau préruminant
}

\author{
par P. GUILloteau, R. TOULLEC, P. PATUREAU-MIRAND *
}

Avec la collaboration technique de Marguerite BEAUFILS, S. BOUSSION, J. LAREYNIE, M. LESAGE et Marie-Claude VALLUY (*)

Station de Recherches Zootechniques, I.N.R.A.,

65, rue de Soint-Brieuc, 35042 Rennes Cedex.

* Laboratoire d'Etudes du Métabolisme Azoté, I.N.R.A., Soint-Genès-Chompanelle, Theix 63110 Beaumont.

Summary. Result of milk and bacteria protein digestion at the end of the small intestine and the digestive tract of the preruminant calf.

Two milk substitutes were prepared containing skim milk powder as the only protein source (control diet) or methanol-grown bacteria which supplied 50.5 p. 100 of the proteins, the rest being provided by the skim milk powder and synthetic amino acids (bacteria diet). Nine Friesian bull calves were used : digestibility was measured at the end of the il eum in 5 , and at the end of the digestive tract in 4. Apparent nitrogen digestibility was lower for bacteria than for milk at the end of the small intestine (86.4 p. $100 \mathrm{vs} 91.3)$ and at the fecal level (90.7 p. 100 vs 95.1 ) (table 1). With both diets, 95 to 96 p. 100 of the nitrogen and 98 to 100 p. 100 of the lipids, apparently digested in the whole digestive tract, were absorbed in the small intestine (table 1). The ileum digesta always contained more threonine, serine, glycine, proline and cystine but less methionine, isoleucine, leucine, tyrosine, phenylalanine, lysine and arginine than the feces (table 2). This might result from higher quantities of endogenous proteins (suggested by the high percentage of threonine in intestinal mucoproteins) and dietary proteins (particularly with the bacteria diet), and also from a lower proportion of gut bacteria proteins (with high lysine, methionine, isoleucine, leucine, tyrosine and phenylalanine content) in digesta than in feces. With the bacteria diet, the excretion supplement computed at the end of the ileum had a very different composition from that of the whole of the dietary bacteria proteins (table 2). Its high content in alanine (19 p. 100) suggested that it might be largely made up of the wall peptidoglycan, whose tetrapeptides contained at least 2 alanine residues in bacteria. In conclusion, the absorption of milk and methanol-grown bacteria nitrogen mainly occurred in the small intestine. The lower digestibility of bacteria protein might be particularly due to their wall peptidoglycan resistance to digestion in the small intestine.

Chez le veau préruminant, les travaux permettant de comparer la digestion des protéines à la fin de l'intestin grêle et à celle du tube digestif sont peu nombreux et concernent exclusivement les protéines du lait (Van Hellemond et Van Weerden, 1973 ; Assan, 1974 ; Van Weerden, Huisman et Van Hellemond, 1977). Le but de cet essai 
était de mesurer à ces deux niveaux, le bilan de la digestion des matières azotées du lait et de bactéries cultivées sur méthanol et de tenter de préciser l'origine des protides apparemment non absorbés, à partir de la composition en acides aminés des matières azotées des fèces et des digesta provenant de la fin de l'iléon.

Deux aliments d'allaitement (Témoin et Bactéries) contenant respectivement 25,3 et 25,5 p. 100 de matières azotées par rapport à la matière sèche, ont été préparés. Dans l'aliment Témoin, les matières azotées étaient apportées exclusivement par de la poudre de lait écrémé ; dans l'aliment Bactéries, elles provenaient pour 50,5 p. 100 de bactéries cultivées sur méthanol, le reste étant fourni par de la poudre de lait écrémé et des acides aminés de synthèse (lysine et méthionine). Quatre veaux mâles de race Frisonne ont été utilisés pour mesurer la digestibilité des aliments dans la totalité du tube digestif. Cinq autres veaux ont été munis d'une canule réentrante dont la partie proximale était placée à la fin de l'iléon et la partie distale dans le cæcum. Deux des veaux de chaque groupe ont d'abord reçu l'aliment Témoin et les autres l'aliment Bactéries. Quatre périodes de mesures ont eu lieu à partir de l'âge de 7 semaines, les régimes étant intervertis à l'issue de la seconde période. Les animaux ont été alimentés en deux repas par jour apportant au total 58 (bilan fèces) ef 53 (bilan iléon) $g$ de matière sèche par $\mathrm{kg}$ de poids vif ${ }^{0,75}$.

La digestibilité apparente de l'azote total est un peu moins élevée pour l'aliment Bactéries que pour l'aliment Témoin, à la fois à la fin de l'iléon et au niveau des fèces (tabl. 1). La digestibilité calculée de l'azote total des bactéries est cependant satisfaisante puisqu'au niveau des fèces, elle est parmi les plus élevées que nous ayons obtenues pour les protéines de substitution (Toullec ef al., 1975). La digestibilité de l'azote des acides aminés est un peu plus élevée que celle de l'azote total, surtout au niveau

TABLEAU 1

Digestibilité des aliments

\begin{tabular}{|c|c|c|c|c|}
\hline \multirow{2}{*}{ Niveau } & \multicolumn{2}{|c|}{ Fin iléon } & \multicolumn{2}{|c|}{ Fèces } \\
\hline & Témoin & Bactéries (1) & Témoin & Bactéries (1) \\
\hline $\begin{array}{l}\text { Nombre total de périodes de mesures.... } \\
\text { Durée des collectes par période........ } \\
\text { Digestibilité apparente (p. 100) }\left({ }^{2}\right): \\
\text { Azote total }\end{array}$ & $\begin{array}{c}9 \\
24 h\end{array}$ & $\begin{array}{c}8 \\
24 h\end{array}$ & $\begin{array}{c}8 \\
10 j\end{array}$ & $\begin{array}{c}8 \\
10 j\end{array}$ \\
\hline $\begin{array}{l}\text { — de l'aliment }\left({ }^{3},{ }^{4}\right) \ldots \ldots \ldots \ldots \ldots \ldots \\
\text { — des bactéries. } \ldots \ldots \ldots \ldots \ldots \ldots \ldots \\
\text { Azote des acides aminés }\left(^{5}\right)\end{array}$ & $\begin{array}{c}91,3(2,1) \\
-\end{array}$ & $\begin{array}{l}88,8(0,8) \\
86,4\end{array}$ & $95,1(0,8)$ & $\begin{array}{l}92,8(0,5) \\
90,7\end{array}$ \\
\hline $\begin{array}{r}\text { - de l'aliment. } \ldots \ldots \ldots \ldots \ldots \ldots \ldots \ldots \\
\text { Lipides }\left({ }^{3}\right) \ldots \ldots \ldots \ldots \ldots \ldots \ldots \ldots \ldots \ldots \ldots \ldots \ldots \ldots\end{array}$ & $\stackrel{93,5}{88,1(4,5)}$ & $\begin{array}{l}91,2 \\
88,5 \\
93,3(2,9)\end{array}$ & $\frac{95,8}{88,3(3,9)}$ & $\begin{array}{l}94,1 \\
92,0 \\
94,8(1,2)\end{array}$ \\
\hline
\end{tabular}

(1) Bactéries cultivées sur méthanol (Pseudomonas methylotropha) (Pruteen, Imperial Chemical Industries Ltd, PO Box 1 Billingham, Cleveland, TS 231 LB, Grande-Brefagne).

( $\left.{ }^{2}\right)$ Moyennes et écarts-types des échantillons.

$\left({ }^{3}, 4\right)$ Différences significatives entre aliments $\left({ }^{3}\right)$ ou entre CUD fin iléon et CUD fèces $\left(^{4}\right)$.

$\left.{ }^{5}\right)$ Acides aminés dosés : a. aspartique, thréonine, sérine, a. glutamique, proline, glycine, alanine, valine, cystine, méthionine, leucine, isoleucine, tyrosine, phénylalanine, lysine, histidine et arginine. 


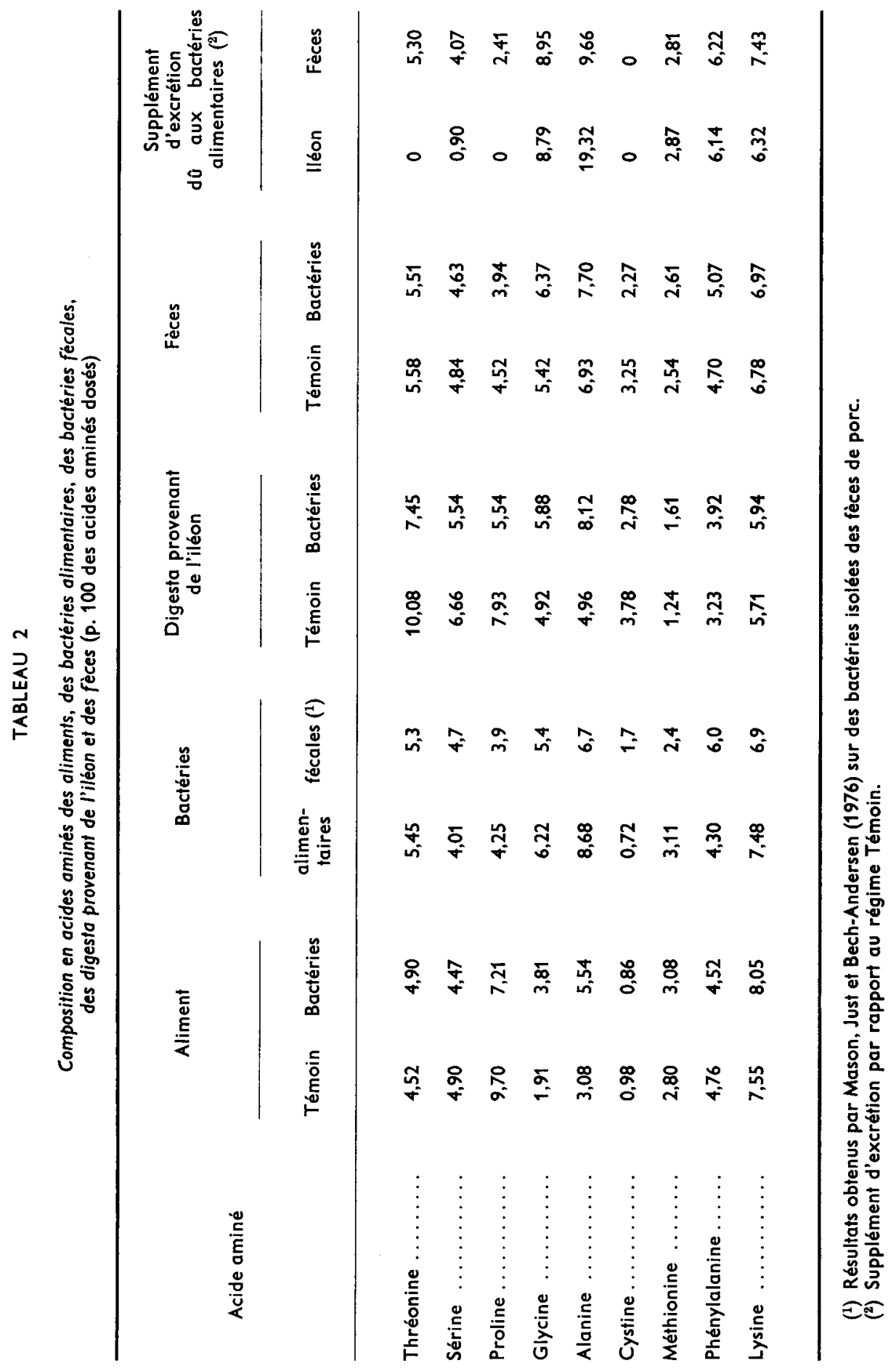


de l'iléon ; seules, celle de la cystine et dans une moindre mesure, celle de la glycine, lui sont systématiquement inférieures. La digestibilité des lipides est au contraire plus élevée pour l'aliment Bactéries ; cela est probablement dû à la teneur moins élevée en acide stéarique des lipides de cet aliment (18,5 au lieu de 23,1 p. 100). Quel que soit l'aliment, une très grande partie (95 à 96 p. 100) de l'azote et la quasi-totalité (98 à 100 p. 100) des lipides apparemment absorbés dans l'ensemble du tube digestif le sont avant la fin de l'intestin grêle, comme l'ont observé Van Hellemond et Van Weerden (1973).

Les digesta provenant de l'iléon sont plus riches en thréonine, sérine, glycine, proline et cystine mais moins pourvus en méthionine, isoleucine, leucine, tyrosine, phénylalanine, lysine et arginine que les fèces (łabl. 2). Ces différences peuvent résulter d'une plus grande quantité de protéines endogènes, suggérée par la teneur élevée en thréonine des mucoprotéines intestinales (Combe et Pion, 1966) et d'une moindre proportion de protéines de bactéries intestinales, riches en lysine, méthionine, isoleucine, leucine, tyrosine et phénylalanine (Mason, Just ef Bech-Andersen, 1976), dans les digesła que dans les fèces. Elles peuvent également provenir d'une plus grande part de protéines alimentaires, surtouł avec l'aliment Bactéries. En admettant que cette part soił très faible avec l'aliment Témoin, le supplément d'excrétion calculé à la fin de l'iléon pour l'aliment Bactéries représenterait les protides des bactéries alimentaires échappant à la digestion dans l'intestin grêle. Cette fraction, particulièrement riche en alanine et pauvre en thréonine, sérine, proline et cystine, a une composition très différente de celle de l'ensemble des protéines des bactéries alimentaires. Elle pourrait correspondre en grande partie au peptidoglycane de la paroi, dont les tétrapeptides contiennent toujours au moins deux résidus alanine, chez les différentes espèces de bactéries qui ont été étudiées (Leive, 1973). Le supplément d'excrétion calculé au niveau des fèces est beaucoup moins caractéristique, du fait des remaniements opérés par la flore dans le gros intestin.

En conclusion, l'absorption des matières azotées du lait et des bactéries cultivées sur méthanol a lieu en très grande partie dans l'intestin grêle. La composition en acides aminés des matières azotées des digesta provenant de la fin de l'iléon est plus intéressante que celle des fèces pour estimer l'origine des protides apparemment non absorbés. La digestibilité moins élevée des protéines des bactéries cultivées sur méthanol semble due en grande partie à la résistance du peptidoglycane de leur paroi à la digestion dans l'intestin grêle.

Commission CNERNA Digestion-Absorption/Associafion des Physiologistes, Paris 5-6 octobre 1978.

\section{Références}

ASSAN E. B., 1974. Contribution ò l'étude de la digestion intestinale de l'amidon chez le veau préruminant. Thèse Doct. Ing. Univ. Clermont-Ferrand, série I, n ${ }^{\circ} 64$.

COMBE E., PION R., 1966. Note sur la composition en acides aminés du contenu de caecum de rats axéniques et de rats témoins. Ann. Biol. anim. Bioch. Biophys., 6, 255-259.

LEIVE L., 1973. The cell enveloppe ; spores, 105-146. In DAVIS B. D., DULBECQ R., EISEN H. N., GINSBERG H. S., WOOD W. B. Microbiology. Harper and Row, Hagerstown, Maryland. 
MASON W. C., JUST A., BECH-ANDERSEN S., 1976. Bacterial activity in the hindgut of pigs. 2. Its influence on the apparent digestibility of nitrogen and amino- acids. Z. Tierphysiol. Tierernähr. Futtermilfel., 36, 310-324.

TOULLEC R., PATUREAU-MIRAND P., THIVEND P., VERMOREL M., 1975. Bases physiologiques de la réalisation des aliments d'allaitement pour veaux. Bull. Soc. scient. Hyg. Alim., 63, 69-100.

VAN HELLEMOND K. K., VAN WEERDEN E. J., 1973. Milk protein substitutes in rations for veal calves. Proc. Nutr. Soc., 32, 231-235.

VAN WEERDEN E. J., HUISMAN J., VAN HELLEMOND K. K., 1977. Verteringsfysiologisch onderzoek. Enkele uitkomsten ten aanzien van hef verteringsprocess in het maagdarmkanaal van het mestkalf. Londbouwk. Tijdsch., 89, 217-224. 